\title{
Biomimetic helical rosette nanotubes and nanocrystalline hydroxyapatite coatings on titanium for improving orthopedic implants
}

\author{
Lijie Zhang' \\ Yupeng Chen² \\ Jose Rodriguez ${ }^{3}$ \\ Hicham Fenniri ${ }^{3}$ \\ Thomas J Webster' \\ 'Division of Engineering, ${ }^{2}$ Department \\ of Chemistry, Brown University, \\ Providence, RI, USA; ${ }^{3}$ National \\ Institute for Nanotechnology and \\ Department of Chemistry, University \\ of Alberta, Edmonton, AB, Canada
}

\begin{abstract}
Natural bone consists of hard nanostructured hydroxyapatite (HA) in a nanostructured protein-based soft hydrogel template (ie, mostly collagen). For this reason, nanostructured HA has been an intriguing coating material on traditionally used titanium for improving orthopedic applications. In addition, helical rosette nanotubes (HRNs), newly developed materials which form through the self-assembly process of DNA base pair building blocks in body solutions, are soft nanotubes with a helical architecture that mimics natural collagen. Thus, the objective of this in vitro study was for the first time to combine the promising attributes of HRNs and nanocrystalline HA on titanium and assess osteoblast (bone-forming cell) functions. Different sizes of nanocrystalline HA were synthesized in this study through a wet chemical precipitation process following either hydrothermal treatment or sintering. Transmission electron microscopy images showed that HRNs aligned with nanocrystalline HA, which indicates a high affinity between both components. Some of the nanocrystalline HA formed dense coatings with HRNs on titanium. More importantly, results demonstrated enhanced osteoblast adhesion on the HRN/ nanocrystalline HA-coated titanium compared with conventional uncoated titanium. Among all the HRN/nanocrystalline HA coatings tested, osteoblast adhesion was the greatest when HA nanometer particle size was the smallest. In this manner, this study demonstrated for the first time that biomimetic HRN/nanocrystalline HA coatings on titanium were cytocompatible for osteoblasts and, thus, should be further studied for improving orthopedic implants.
\end{abstract}

Keywords: helical rosette nanotubes, nanocrystalline hydroxyapatite, biomimetic, titanium, osteoblast, self assembled

\section{Introduction}

Although conventionally synthesized biomaterials have been served well as orthopedic implants over the past half a century, high implant failure rates after 10-15 years of implantation necessitate improvement. For example, in the United States, nearly $11 \%$ of hip replacements and $8 \%$ of knee replacements were revision procedures of previously failed replacements in 2003 (AAOS 2003). One of many reasons for implant failure is the incompatibility between osteoblasts (bone-forming cells) and today's implant materials such as titanium (Jayaraman et al 2004). One approach to improve such implant materials is to design implants which are more similar to natural bone, and this is a role envisioned for nanotechnology. To date, nanomaterials (that is, materials with basic structural units, grains, particles, fibers, or other constituent components in the range of 1-100 nm [Siegel and Fougere 1995]) have exhibited enhanced cytocompatibility, mechanical, and electrical properties compared with respective conventional micronscale materials. The nanostructural features, favorable surface chemistry, and bioactive surfaces of nanomaterials which mimic bone significantly promote selective protein (such as vitronectin, fibronectin, etc) adsorption and efficiently stimulate new 
bone formation compared with conventional materials, thus, possibly serving as the next generation of orthopedic implant materials (Zhang et al 2008a).

One type of novel nanomaterial, helical rosette nanotubes (HRNs), are novel organic nanotubes that mimic the natural nanostructure of collagen and other components in bone. The DNA base pair building blocks of HRNs (the guaninecytosine motif) undergo self-assembly in body solutions to form a stable nanotube with a $3.5 \mathrm{~nm}$ outer diameter tube based on hydrogen bond formation, base-stacking interactions and hydrophobic effects (Figure 1) (Fenniri et al 2001). Not only are HRNs biologically-inspired nanometric and helical architectures similar to collagen in bone, but they also can be functionalized with a diverse range of peptides (such as arginine-glycine-aspartic acid [RGD] and lysine) which have been known to enhance osteoblast functions. Previous studies have demonstrated the ability of HRNs to increase osteoblast adhesion as a coating material on titanium (Chun et al 2004, 2005).

Another major component in the bone matrix is hydroxyapatite $\left(\mathrm{HA} ; \mathrm{Ca}_{10}\left(\mathrm{PO}_{4}\right)_{6}(\mathrm{OH})_{2}\right)$ which has been used as an orthopedic and dental implant material for decades (Hoexter 2002; Sammarco and Chang 2002). HA is osteoconductive since its surface can undergo selective chemical reactivity with surrounding tissues, which results in a tight bond between bone and the implant. Moreover, studies have demonstrated that HA induced osteogenic differentiation of osteoblasts (Wang 2004). Recently, studies have further improved HA for orthopedic applications by coating nanometer (instead of micron) HA crystals on titanium matching the crystal size of HA in bone. Nanophase HA has excellent cytocompatibility properties with osteoblasts (Chang et al 2006) and in vivo studies have demonstrated complete osseointegration of tantalum coated with nanophase HA after 2 weeks whereas tantalum coated with conventional (or micron) HA took up to 8 weeks (Sato 2006). As a result, these promising properties of nanophase HA and HRNs have highlighted the possibility that collectively they should be studied for orthopedic applications.

Thus, the objective of this study was to determine material and cytocompatibility properties (with osteoblasts) of HRN/ HA composites. In this study, a wet chemistry precipitation method was used to synthesize HA (Lopez-Macipe et al 1998; Sato et al 2006). This process, via a mild reaction under room temperature, is similar to the biomineralization process of bone and teeth. In addition, wet chemistry enabled good control of the crystalline phase and surface morphology of $\mathrm{HA}$ at the micrometer and nanometer levels (Duan and Wang 2006). Moreover, since grain size is one of the important factors which may influence the growth of osteoblasts on implant materials, several grain sizes of nanocrystalline HA in HRNs were fabricated here by utilizing different sintering temperatures or hydrothermal treatment regimes.

\section{Materials and methods Synthesis of HA and preparation of HRNs}

A well-established wet chemistry process was used to synthesize HA (Lopez-Macipe et al 1998; Sato et al 2006). Briefly, $37.5 \mathrm{ml}$ of a $0.6 \mathrm{M}$ ammonium phosphate (Sigma Aldrich, St. Louis, MO) solution was mixed with $375 \mathrm{ml}$ of deionized water $\left(\mathrm{dH}_{2} \mathrm{O}\right)$ while ammonium hydroxide (Fisher Scientific, Waltham, MA) was used to adjust the solution $\mathrm{pH}$ to around $10.45 \mathrm{ml}$ of a $1 \mathrm{M}$ calcium nitrate (Sigma Aldrich) solution was slowly dripped into the above mixture over 12 min while stirring. Precipitation of HA continued
(A)

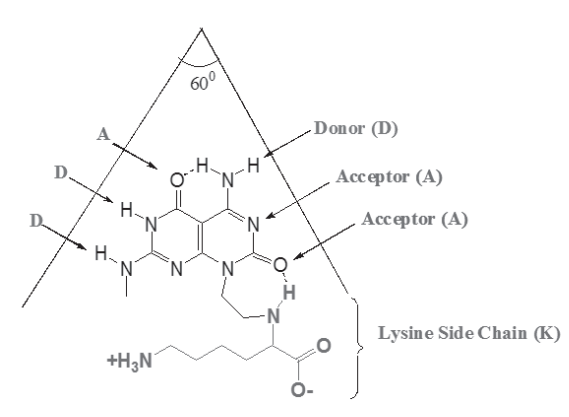

(B)

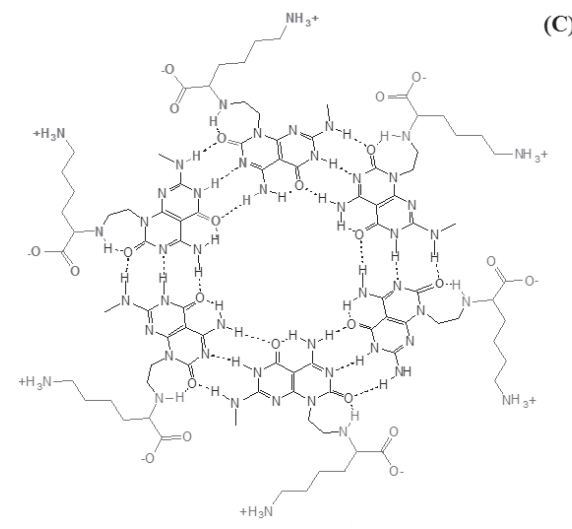

(C)

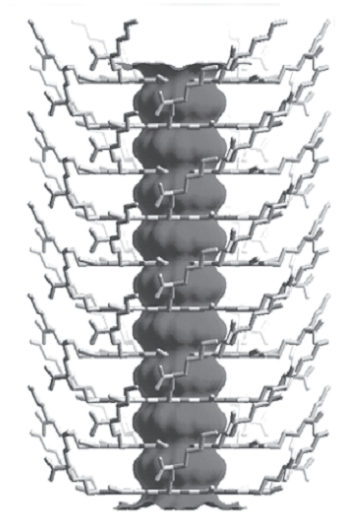

Figure I Schematic illustration of the hierarchical assembly of HRNs with a lysine side chain (HRN-KI). (A) The DNA base pair building blocks (Guanine-cytosine, G^C motif) and lysine side chain, (B) Six $\mathrm{G}^{\wedge} \mathrm{C}$ motifs assemble into a rosette supermacrocycle by the formation of $18 \mathrm{H}$-bonds, and (C) The rosettes stack up to form a stable $3.5 \mathrm{~nm}$ diameter HRN with a II A inner tube channel. 
for $10 \mathrm{~min}$ at room temperature. Then, the solution with HA precipitates was treated hydrothermally at $200{ }^{\circ} \mathrm{C}$ for $20 \mathrm{~h}$ in a $125 \mathrm{ml}$ Teflon liner (Parr Instrument, Moline, IL) (Ioku and Yoshimura 1991). This hydrothermal treatment method produced small grain sizes of nanocrystalline HA at relatively low temperatures but under a higher pressure (Sato et al 2005). After $20 \mathrm{~h}$, the nanocrystalline HA was centrifuged and rinsed sequentially with $\mathrm{dH}_{2} \mathrm{O}$ three times, then dried at $80^{\circ} \mathrm{C}$ for $12 \mathrm{~h}$.

Larger grain sizes and higher yield rates of nano HA can be obtained without hydrothermal treatment. For this, $1 \mathrm{M}$ calcium nitrate was slowly added to $0.6 \mathrm{M}$ ammonium phosphate, while ethanol was used to disperse the mixture and ammonium hydroxide to adjust the $\mathrm{pH}$ up to 12 . The mixture was then slightly heated at $40{ }^{\circ} \mathrm{C}$ for $1 \mathrm{~h}$ and HA precipitated at room temperature for $24 \mathrm{~h}$. The HA white powder was obtained after washing and centrifugation and was dried similar to the method described above. Then, the HA powder was sintered at $700{ }^{\circ} \mathrm{C}$ for $6 \mathrm{~h}$ to achieve a large nanocrystalline HA grain size or at $550{ }^{\circ} \mathrm{C}$ for $6 \mathrm{~h}$ to produce a middle nanocrystalline HA grain size.

HRNs with lysine side chain (HRN-K1) building blocks were synthesized by using a general synthetic strategy (Fenniri et al 2001). In total, six main intermediate products were synthesized in 16 steps of synthesis reactions to obtain HRN-K1 building blocks. Then, HRN-K1 building blocks were dissolved in $\mathrm{dH}_{2} \mathrm{O}$ to achieve a $0.1 \mathrm{mg} / \mathrm{ml}$ stock solution. $0.001 \mathrm{mg} / \mathrm{ml}$ HRN-K1 solution was prepared by diluting the stock solution with $\mathrm{dH}_{2} \mathrm{O}$. Solutions were sterilized with a $0.22 \mu \mathrm{m}$ syringe filter (Chun et al 2004).

\section{HRN and HA coatings on titanium}

Titanium (Ti, $1 \mathrm{~cm} \times 1 \mathrm{~cm} \times 0.2 \mathrm{~cm}$; SupraAlloys, Camarillo, CA) was cleaned according to standard procedures (Chun et al 2004). $250 \mathrm{mg}$ of each type of nano HA (specifically, small, middle and large HA grain sizes) was mixed with $5 \mathrm{ml} 70 \%$ ethanol and sonicated for $20 \mathrm{~min}$ to obtain a homogenous HA solution. Then, $5 \mathrm{ml}$ of $0.001 \mathrm{mg} / \mathrm{ml}$ HRN-K1 solution was added into each of the above mixtures. Nano HA and HRN-K1 were coated on the titanium surface by absorption for 45 minutes at room temperature and dried overnight. In addition, $0.001 \mathrm{mg} / \mathrm{ml}$ HRN-K1 without HA was coated on titanium. Uncoated titanium served as controls.

\section{HRN and HA characterization}

HRNs have been fully characterized as described elsewhere (Fenniri et al 2001; Chun et al 2004, 2005). The nanocrystalline HA powders were characterized by
X-ray diffraction (XRD; Siemens Diffraktometer D5000). Nanocrystalline HA, HRNs, and the combination of HRNs with nano HA were characterized with TEM (Philips, EM410 PW6008). The agglomerated mean particle size was determined by a particle size analyzer (Nano ZS, Malvern Instruments). The HRN/nanocrystalline HA coatings were characterized with SEM (LEO 1530-VP).

\section{Osteoblast experiments}

Osteoblast adhesion was determined on: (1) $0.001 \mathrm{mg} / \mathrm{ml}$ HRN-K1 with the small grain size nanocrystalline HA (prepared by the hydrothermal treatment) coated on titanium, (2) $0.001 \mathrm{mg} / \mathrm{ml} \mathrm{HRN-K1}$ with the middle grain size nano $\mathrm{HA}$ (prepared by sintering at $550^{\circ} \mathrm{C}$ ) coated on titanium, (3) $0.001 \mathrm{mg} / \mathrm{ml} \mathrm{HRN}-\mathrm{K} 1$ with the large grain size nanocrystalline HA (prepared by sintering at $700^{\circ} \mathrm{C}$ ) coated on titanium, (4) $0.001 \mathrm{mg} / \mathrm{ml} \mathrm{HRN}-\mathrm{K} 1$ alone coated on titanium, and (5) uncoated titanium. Human fetal osteoblasts (bone-forming cells, ATCC, CRL-11372, population numbers 8-10) were seeded at 3500 cells $/ \mathrm{cm}^{2}$ onto the above five substrates and were cultured in Dulbecco's modified eagle's medium (DMEM; Gibco/BRL, Grand Island, NY) supplemented with 10\% fetal bovine serum (FBS; HyClone, Logan, UT) and $1 \%$ penicillin/streptomycin $(\mathrm{P} / \mathrm{S}$; Hyclone) under standard cell culture conditions $\left(37{ }^{\circ} \mathrm{C}\right.$, a humidified, $5 \% \mathrm{CO}_{2} / 95 \%$ air environment) for $4 \mathrm{~h}$. After the prescribed time period, nonadherent cells were removed by washing with phosphate buffered saline (PBS). Adherent cells were then fixed with $10 \%$ normal buffered formalin (NBF; Fisher Scientific), stained with 4',6-diamidino-2-phenylindole, dihydrochloride (DAPI; Invitrogen, Carlsbad, CA) and counted on five random fields of view for each substrate using a Zeiss Axiovert 200M fluorescence microscope.

\section{Statistical analysis}

Experiments were run in triplicate and repeated three separate times for each substrate. Data were represented by the mean value with the standard error of the mean (SEM) noted. A student's t-test was used to check statistical significance between means and $\mathrm{p}<0.1$ was considered statistically significant.

\section{Results and discussion \\ Particle synthesis and the affinity between HRN-KI and HA}

In the present study, different grain sizes and morphologies of nanocrystalline HA were synthesized using two treatment 
methods. TEM images showed that HA precipitates did not have clear demarkation lines or regular shapes before hydrothermal treatments or sintering (Figure 2A). Rod-like nanocrystalline HA particles were synthesized after hydrothermal treatment ( $\sim 50-100 \mathrm{~nm}$ in length and 20-30 nm in width; Figure 2B) and after sintering at $700{ }^{\circ} \mathrm{C}$ for $6 \mathrm{~h}$
( $100-170 \mathrm{~nm}$ in length and 20-30 nm in width; Figure 2D). In addition, sintering $\mathrm{HA}$ powers at $550^{\circ} \mathrm{C}$ for $6 \mathrm{~h}$ produced a middle grain size of irregular nanocrystallized HA with a more agglomerated morphology (Figure 2C). Most importantly, Figure 2E showed for the first time a good affinity between HRN-K1 and nanocrystalline HA. Specifically, a
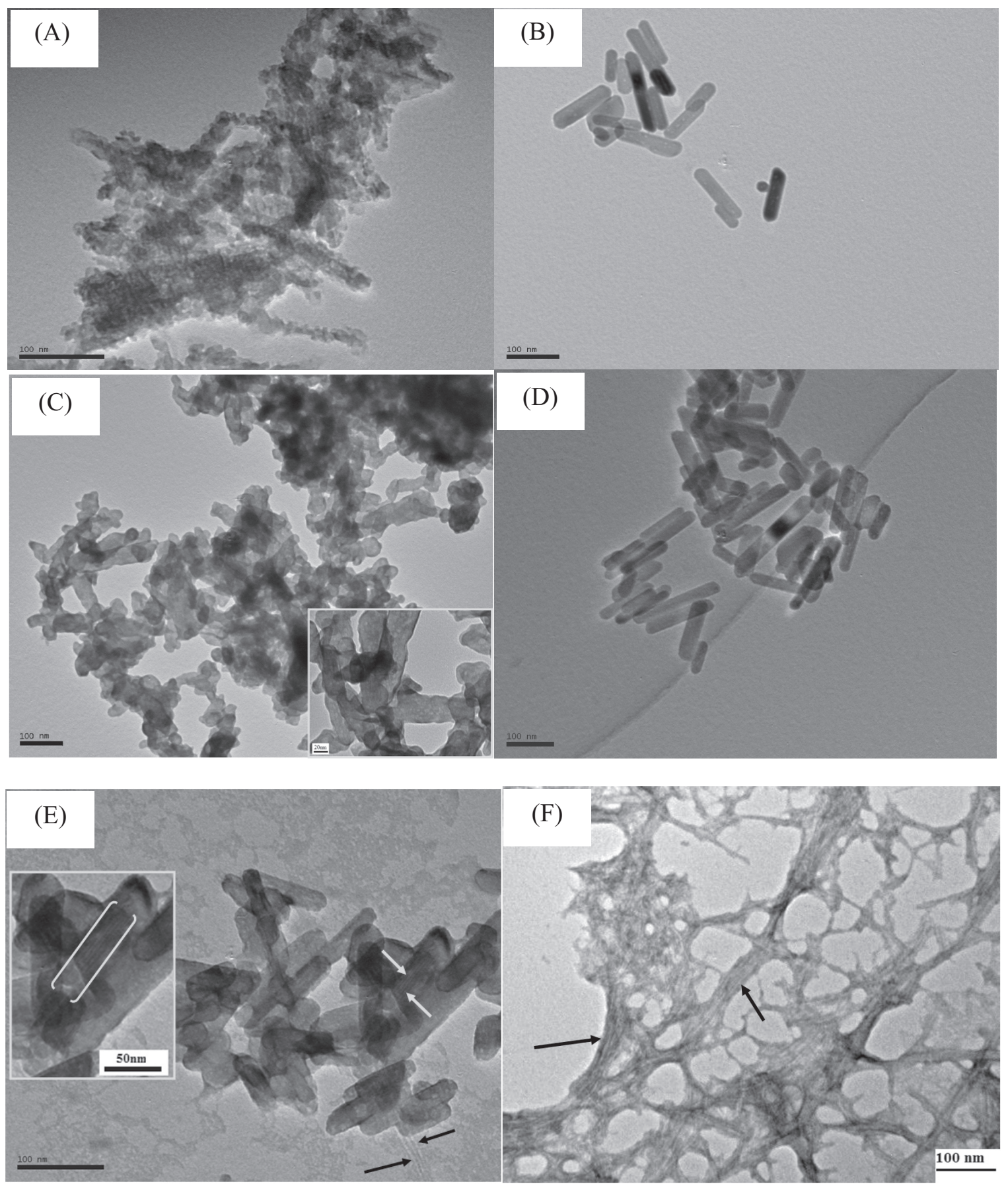

Figure 2TEM images of (A) HA precipitates before sintering, (B) small grain size nanocrystalline HA (prepared by hydrothermal treatment), (C) middle grain size nanocrystalline HA (prepared by sintering at $550^{\circ} \mathrm{C}$ ) with the inset at high magnification, scale bar of the inset image is $20 \mathrm{~nm}$, (D) large grain size nanocrystalline HA (prepared by sintering at $700{ }^{\circ} \mathrm{C}$ ), (E) $0.01 \mathrm{mg} / \mathrm{ml} \mathrm{HRN-KI}$ with small grain size nanocrystalline HA (hydrothermal treatment nano HA served as a model); inset shows the enlarged region of (E) demonstrating the close HRN/HA interaction, and (F) $0.01 \mathrm{mg} / \mathrm{ml} \mathrm{HRN-KI}$ only. Arrows show the HRN-KI. 
bundle of HRN-K1 attached and oriented on nanocrystalline HA surfaces by simple adsorption.

Furthermore, by measuring the sizes of nanocrystalline HA in TEM images, Figure 3 provided quantified results of the average HA grain sizes after hydrothermally treatment and sintering which demonstrated that hydrothermal treatment can yield much smaller crystallite sizes than other methods. Specifically, nanocrystalline HA prepared by the hydrothermal treatment had an average grain size of $82.84 \mathrm{~nm}$ (in length) while nanocrystalline HA particles prepared by sintering at either $550{ }^{\circ} \mathrm{C}$ or $700{ }^{\circ} \mathrm{C}$ had average grain sizes of $90.01 \mathrm{~nm}$ and $129.81 \mathrm{~nm}$, respectively.

In addition, XRD provided evidence that crystalline HA was present in all particles (Figure 4). Hydrothermally treated nanocrystalline HA displayed small amounts of peak broadening (Figure 4A), which supports the previously mentioned data of smaller crystallite sizes of hydrothermal nano HA compared with the other two types of sintered nano HA (Figure 4B and 4C). Moreover, consistent with previous studies (Sato et al 2006; Balasundaram et al 2006), all types of nanocrystalline HA agglomerated into micron sizes and hydrothermally prepared nanocrystalline HA agglomerated into smaller sizes than sintered nanocrystalline HA. Specifically, hydrothermally treated HA and HA sintered at either $550{ }^{\circ} \mathrm{C}$ or at $700{ }^{\circ} \mathrm{C}$ had $\sim 1.51,3.32$, and $1.61 \mu \mathrm{m}$ agglomerated mean particle sizes (Table 1), respectively. A previous study demonstrated that conventional (or micron)
HA agglomerated up to $169 \mu \mathrm{m}$ (Balasundaram et al 2006). The significant larger agglomeration sizes of the middle grain sizes nanocrystalline HA may be due to more irregular shapes of HA and possibly greater hydrophobic surface chemistry that increased agglomeration after sintering at $550{ }^{\circ} \mathrm{C}$ when compared with the regular rod-like hydrothermal HA. Moreover, Table 1 showed that sintering HA precipitates to either $550{ }^{\circ} \mathrm{C}$ or $700^{\circ} \mathrm{C}$ achieved higher yield rates of nanocrystalline HA $(86.46 \%$ and $83.51 \%)$ than nanocrystalline HA prepared by hydrothermal treatments (69.54\%). The longer HA precipitation time (24 h) before sintering most likely contributed to the higher yield rates of nanocrystalline HA prepared by sintering (whereas only a 10 minute precipitation was used for the hydrothermal treatment).

\section{Characterization of HRN and HA coatings on titanium}

SEM images showed that thin layers of different size distributions of nanocrystalline HA in $0.001 \mathrm{mg} / \mathrm{ml} \mathrm{HRN-K1}$ were coated on titanium (Figure 5). All of the nanocrystalline HA with HRN coatings exhibited agglomerated nanocrystallites. Uncoated titanium had micron roughness with large grain sizes; specifically, small grain sizes of nanocrystalline HA with HRNs revealed dense HA rod crystallite agglomerations (Figure 5A and 5B). Middle grain sizes of nanocrystalline HA with HRN coatings also showed very

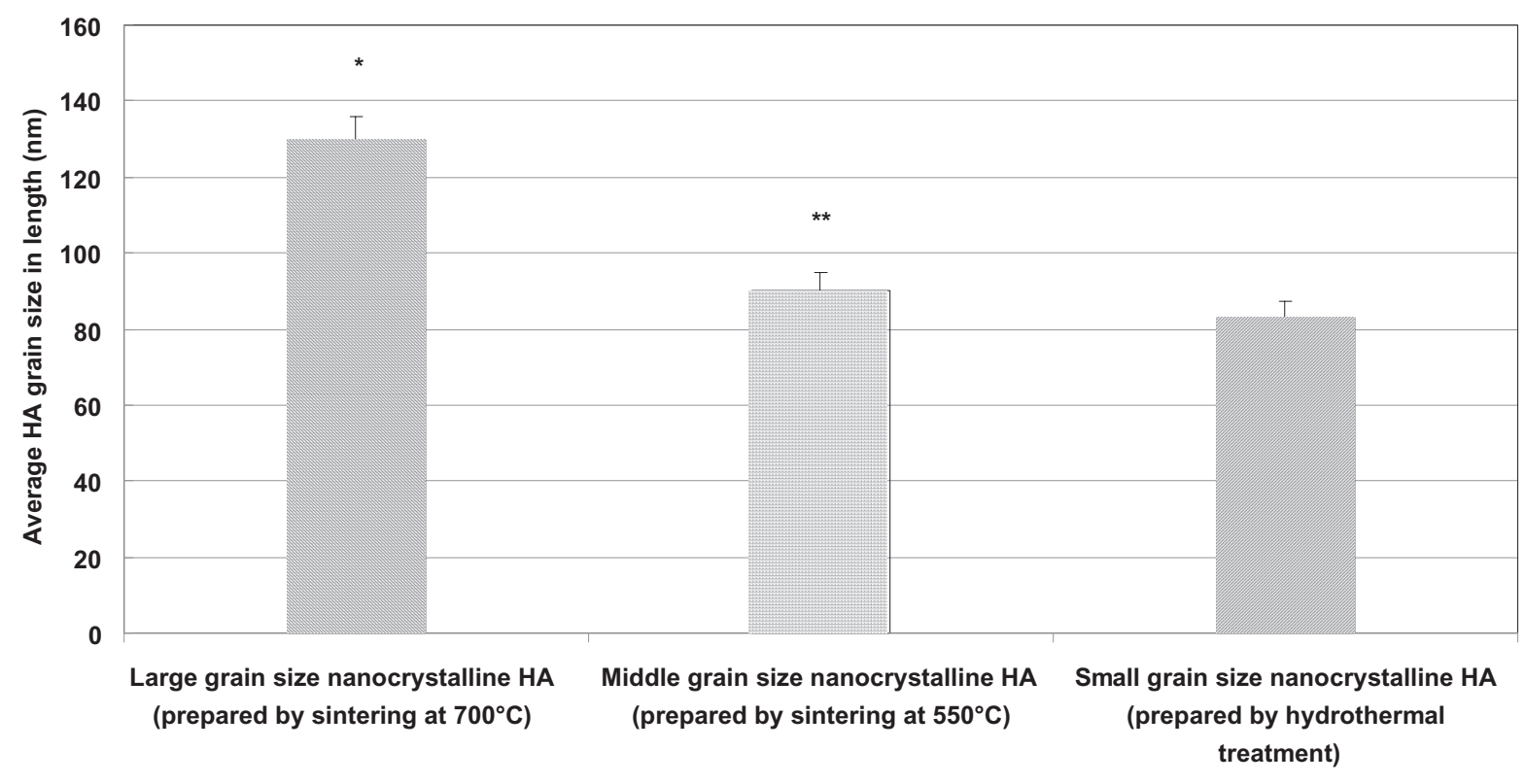

Figure 3 The comparison of average grain sizes of nanocrystalline HA under different synthesis treatments. Data are mean \pm SEM; $n=50$. *p $<0.000$ I when compared with small grain size nanocrystalline HA (prepared by hydrothermal treatment), and **p $<0.000$ I when compared with large grain size nanocrystalline $\mathrm{HA}$ (prepared by sintering at $\left.700^{\circ} \mathrm{C}\right)$. 


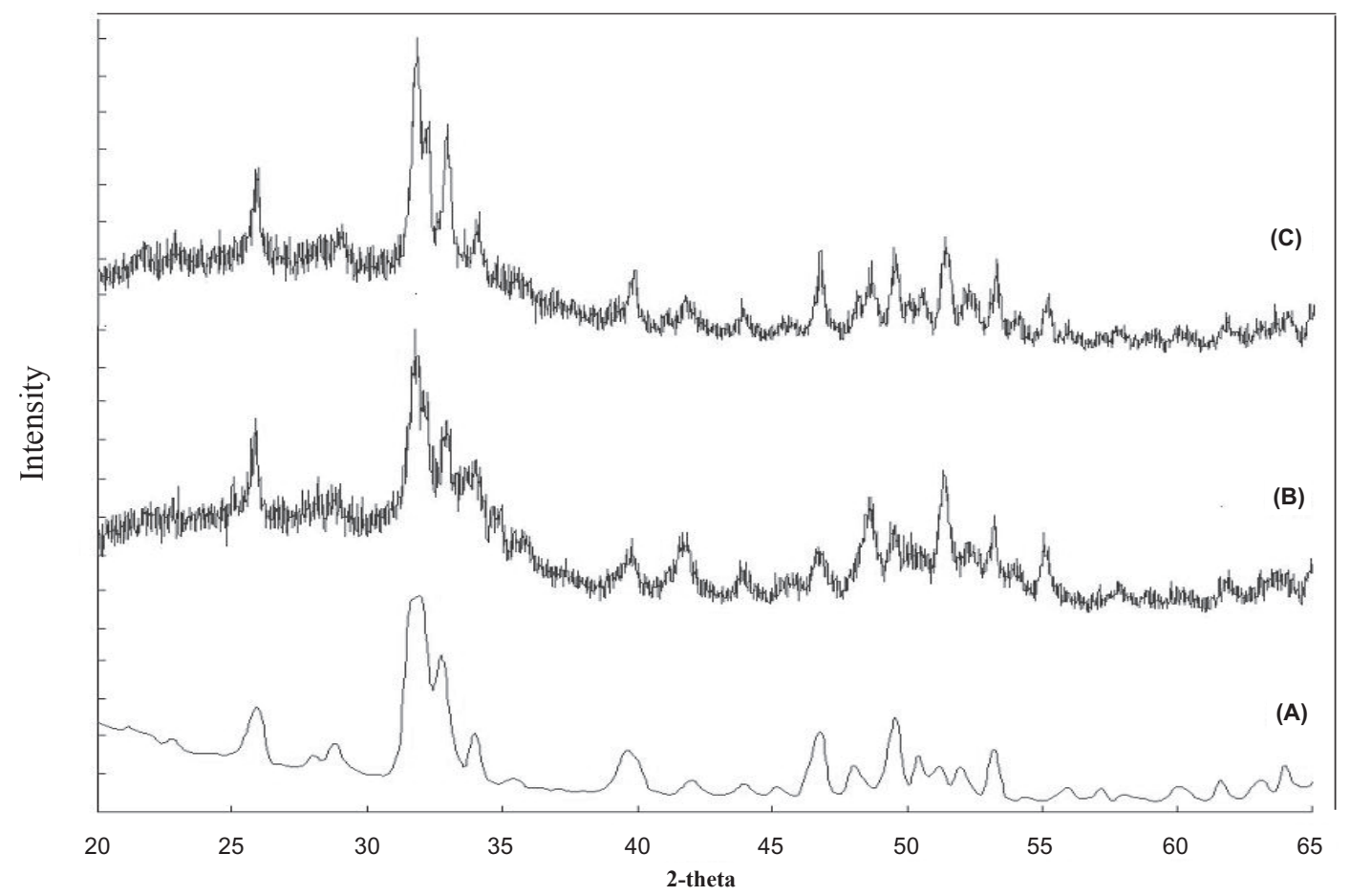

Figure 4 XRD of nanocrystalline HA. (A) Small grain size nanocrystalline HA (prepared by hydrothermal treatment), (B) middle grain size nanocrystalline HA (prepared by sintering at $550^{\circ} \mathrm{C}$ ), and $(\mathbf{C})$ large grain size nanocrystalline $\mathrm{HA}$ (prepared by sintering at $700^{\circ} \mathrm{C}$ ).

dense crystallite agglomerations but irregular crystalline distributions (Figure 5C and 5D) which was consistent with TEM and Table 1 results. In contrast, large grain sizes of nanocrystalline HA with HRN coatings exhibited the largest HA rod crystallite assemblies with a loose connecting pattern compared with the other coatings (Figure 5E and 5F). TEM clearly demonstrated intimate interactions between HRNs and HA when coated on titanium.

\section{Osteoblast adhesion}

Results from the cytocompatibility tests provided the first evidence of greater osteoblast adhesion on nanocrystalline HA/HRN coatings on titanium compared with uncoated titanium (Figure 6). Specifically, the small and middle grain sizes of nanocrystalline HA/HRN coatings increased osteoblast adhesion by $29.3 \%$ and $36.3 \%$ on titanium compared with uncoated titanium, respectively. At the same time, the small and middle grain size nanocrystalline HA/HRN coatings also increased osteoblast adhesion more than on the large grain size nanocrystalline HA/HRN coatings. In fact, it has been demonstrated that nanophase materials improved specific protein (such as fibronectin and vitronectin) interactions which contributed to enhanced osteoblast functions on nanophase materials compared with large grain size conventional materials (Webster et al 2000). For example, Webster and colleagues (2000) showed that there was significantly enhanced osteoblast adhesion on bulk nanophase HA $(67 \mathrm{~nm})$ compared with conventional HA (179 nm HA) due to greater

Table I Summary of the nanocrystalline HA yield rates, grain and agglomerated sizes

\begin{tabular}{llll}
\hline Types & Yield rates & Average grain sizes & Agglomerated mean size \\
\hline $\begin{array}{l}\text { Small grain size nanocrystalline HA } \\
\text { (hydrothermally treated at } 200^{\circ} \mathrm{C} \text { for } 20 \mathrm{~h} \text { ) }\end{array}$ & $69.54 \%$ & $82.84 \mathrm{~nm}$ & $1512.5 \mathrm{~nm}$ \\
$\begin{array}{l}\text { Middle grain size nanocrystalline HA } \\
\left(\text { sintered at } 550^{\circ} \mathrm{C} \text { for } 6 \mathrm{~h} \text { ) }\right.\end{array}$ & $86.46 \%$ & $90.01 \mathrm{~nm}$ & $3323.5 \mathrm{~nm}$ \\
$\begin{array}{l}\text { Large grain size nanocrystalline HA } \\
\left(\text { sintered at } 700^{\circ} \mathrm{C} \text { for } 6 \mathrm{~h}\right)\end{array}$ & $83.51 \%$ & $129.81 \mathrm{~nm}$ & $1609.9 \mathrm{~nm}$ \\
$\begin{array}{l}\text { HA precipitates (before hydrothermal } \\
\text { treatment or sintering) }\end{array}$ & - & $113.64 \mathrm{~nm}$ & $2278.6 \mathrm{~nm}$ \\
\hline
\end{tabular}



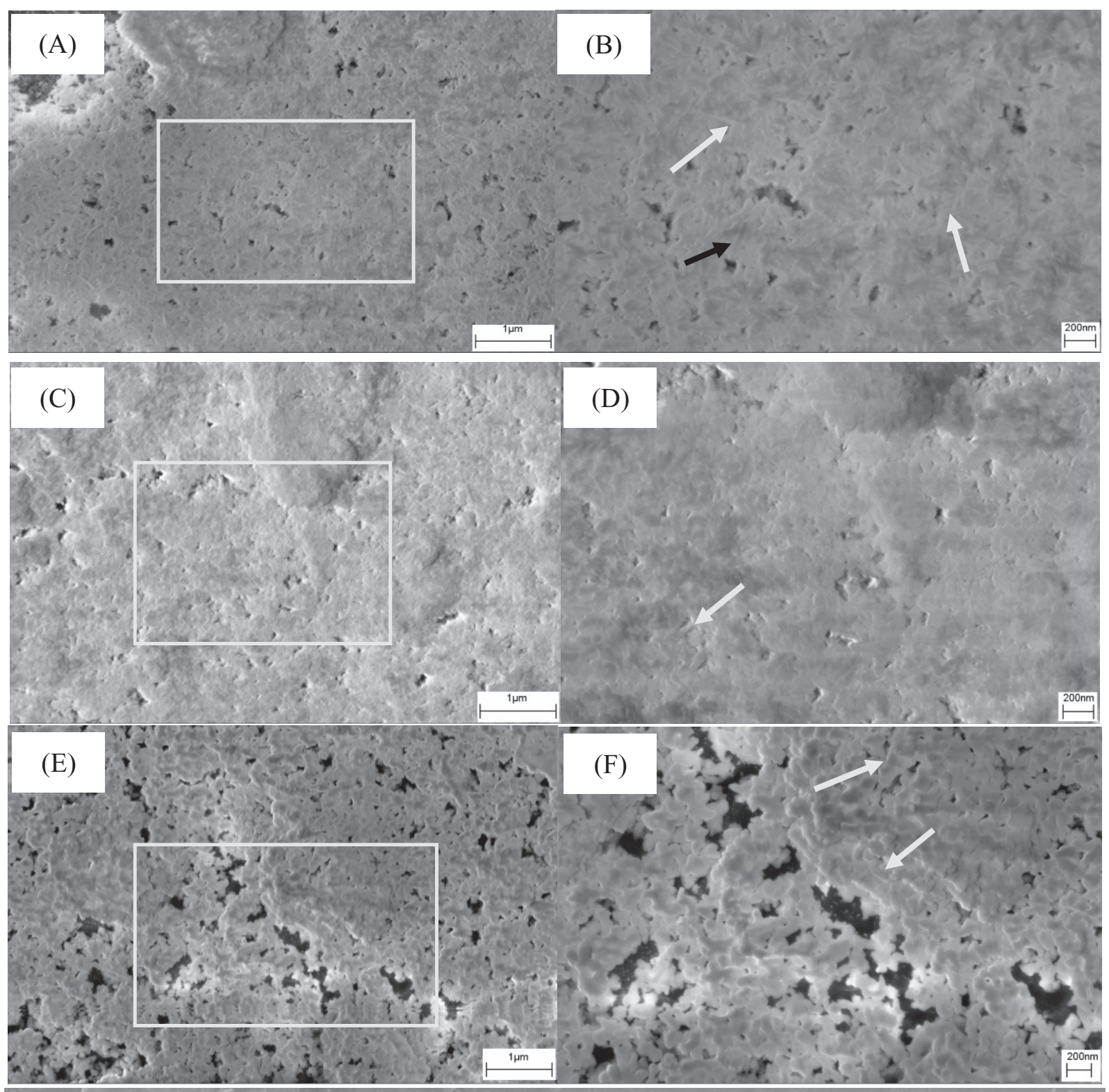

(G)

$(\mathrm{H})$
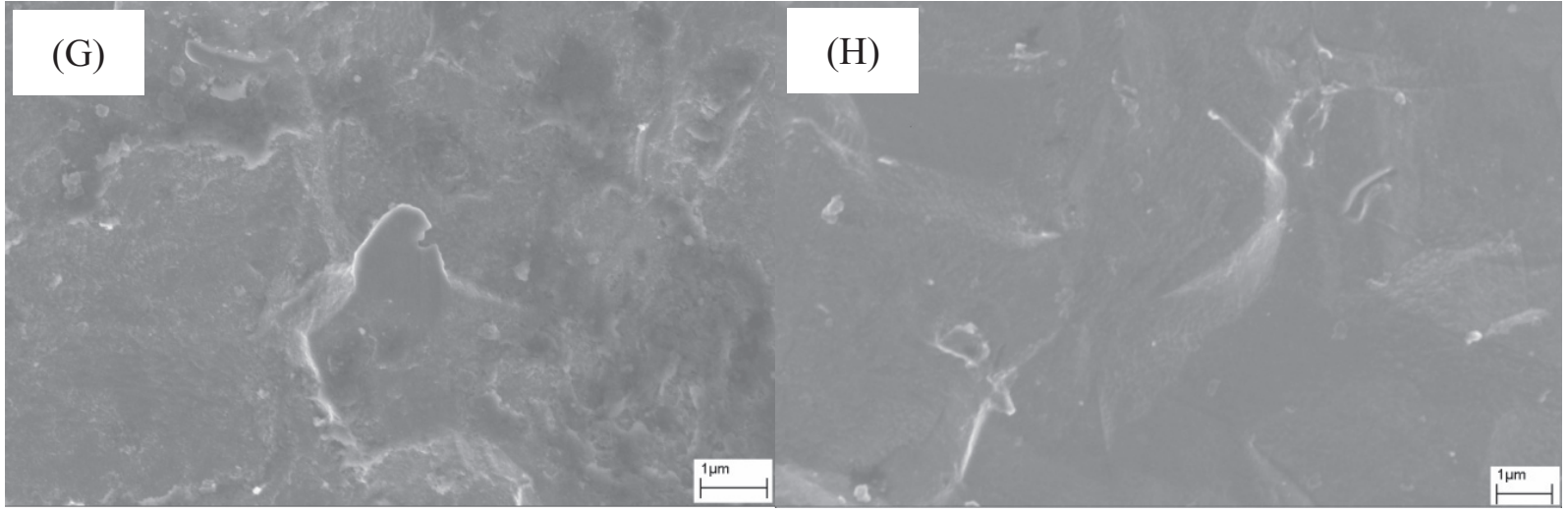

Figure 5 SEM micrographs of (A) low magnification and (B) high magnificaition small grain size nanocrystalline HA (prepared by hydrothermal treatment) with $0.00 \mathrm{I} \mathrm{mg} / \mathrm{ml}$ HRN-KI coated on titanium; (C) low magnification and (D) high magnification of middle grain size nanocrystalline $\mathrm{HA}$ (prepared by sintering at $550^{\circ} \mathrm{C}$ ) with $0.00 \mathrm{I} \mathrm{mg} / \mathrm{ml} \mathrm{HRN}-\mathrm{KI}$ coated on titanium; (E) low magnification and $(\mathbf{F})$ high magnificaition of large grain size nanocrystalline HA (prepared by sintering at $700{ }^{\circ} \mathrm{C}$ ) with $0.00 \mathrm{I} \mathrm{mg/ml} \mathrm{HRN-KI} \mathrm{coated}$ on titanium; (G) titanium coated with $0.001 \mathrm{mg} / \mathrm{ml} \mathrm{HRN}-\mathrm{KI}$ and $(\mathbf{H})$ uncoated titanium. Arrows show the single HA crystallites. 


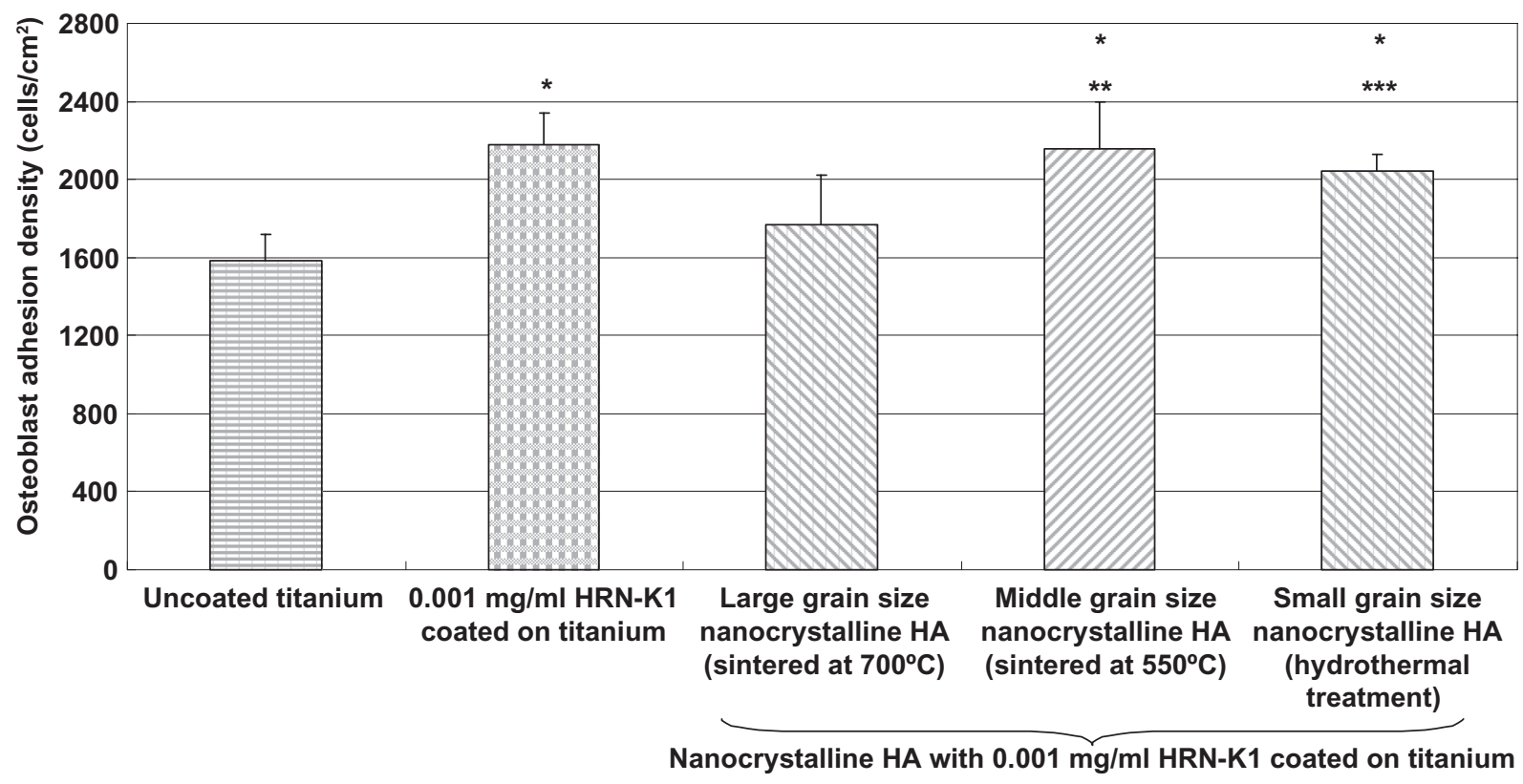

Figure 6. Osteoblast adhesion on HA and HRN-KI-coated titanium. Data are mean $\pm \mathrm{SEM} ; \mathrm{n}=9$.

Notes: ${ }^{*} \mathrm{p}<0.05$ when compared to uncoated titanium; ${ }^{* *} \mathrm{p}<0.0 \mathrm{I}$ and ${ }^{* * *} \mathrm{p}<0.1$ when compared with large grain size nanocrystalline $\mathrm{HA}$ (prepared by sintering at $700^{\circ} \mathrm{C}$ ) with $0.001 \mathrm{mg} / \mathrm{ml} \mathrm{HRN}-\mathrm{KI}$ coated on titanium.

amounts of vitronectin (a protein known to mediate anchorage-dependent cell adhesion [Webster 2001]) adsorption.

In the present study, a grain size-dependent osteoblast adhesion was also observed for the small and middle grain sizes of nano HA/HRN coatings compared with the large grain size HA/HRN coatings. In addition, osteoblast attachment significantly improved on the $0.001 \mathrm{mg} / \mathrm{ml} \mathrm{HRN-K1}$ coated titanium (alone) which is consistent with previous studies (Chun et al 2004, 2005). Importantly, although the bone remodeling process in vivo includes various cell types (such as osteoblasts, osteoclasts, and osteocytes) (Webster 2001), promoting initial osteoblast adhesion on orthopedic implant materials is essential for further new bone growth. Therefore, the significantly enhanced osteoblast adhesion on nanocrystalline HA/HRN coatings observed in this study indicates promise for the continued investigation of these biomimetic coatings for improving orthopedic implants. Clearly, however, future studies will have to evaluate the long-term functions of osteoblasts as well as determine the functions of additional cells necessary for maintaining healthy, strong bones in the body.

As is known, inorganic nanocrystalline HA and elastic collagen (which has helical nanostructures) assemble to form the natural bone matrix (Kaplan et al 1994; Webster 2001). Thus, much effort has been devoted to apply bioactive and osteoconductive nano HA materials as coatings on implant materials for orthopedic applications (Webster et al 2002;
Choi et al 2004; Bigi et al 2005; Sato et al 2005, 2006, 2007; Balasundaram et al 2006; Evis et al 2006; Narayanan et al 2008; Teng et al 2008; Ciobanu et al 2007; Shibli and Mathai 2008). For instance, recently it has been reported that enhanced cell functions were observed on titanium coated with nano HA by an electrochemical method (Narayanan et al 2008). However, current HA coatings still can not satisfy patients' high expectations for orthopedic implants due to many shortcomings (ie, lack of rapid osseointegration, low degree of crystallinity, weak interactions with titanium, etc). In this study, it should be emphasized that novel nanotubular HRNs, which are coated with a high degree of nanocrystalline HA on titanium, not only possess flexible functionalizable chemistries but also have biologically-inspired surface features which may create favorable bone-like environments to improve osseointegration with juxtaposed bone.

For instance, HRNs have potential to serve as a biomimetic template for HA deposition. Figure $7 \mathrm{C}$ shows that HA crystals were rapidly formed on HRNs when mixed with $\mathrm{CaCl}_{2}$ and $\mathrm{Na}_{2} \mathrm{HPO}_{4}$ solutions for 2 minutes and were regularly aligned on HRNs in a pattern similar to the HA/collagen pattern in bone. Figure 7D shows randomly agglomerated HA on grids without HRNs. Because the deposition, nucleation and growth of HA crystals in pores of an extracellular collagen matrix are important steps during bone remodeling in vivo, it can be anticipated that the HRN/HA coatings formulated in this study not only mimic the nanostructure of bone 
but also resemble the HA/collagen self-assembly process to promote natural mineralization (Figure 7).

In addition, although there were no statistical differences in osteoblast adhesion among the HRNs coated on titanium and nanocrystalline HA/HRN coated on titanium (due to the possibly different concentrations of exposed HRNs on their surfaces), creating a biomimetic coating on titanium is promising to promote osteoblast adhesion and long term

(A)

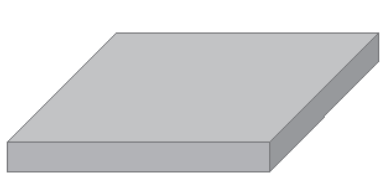

Titanium

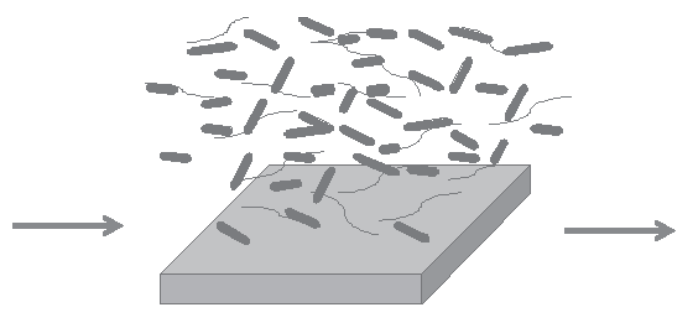

Coating nano HA and HRNs on titanium

(B)

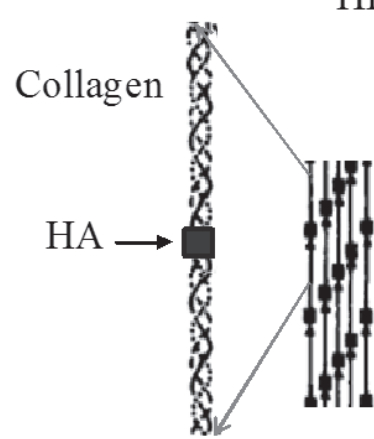

Triple helix of collagen and nano HA crystals in the bone matrix

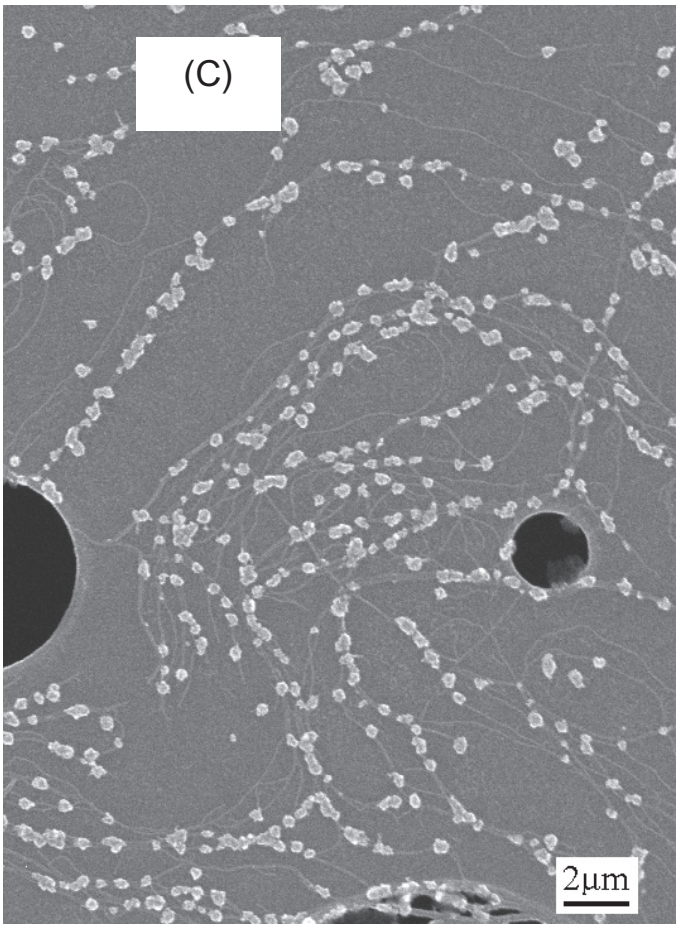

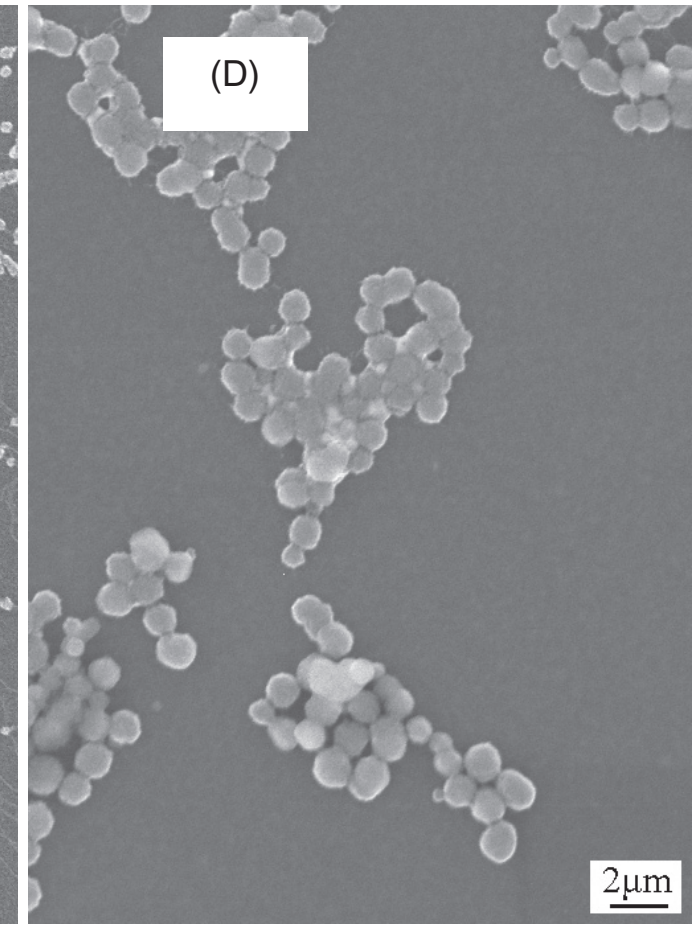

Biologically-inspired helical rosette nanotubes and nanocrystalline HA coating

Figure 7 A biologically-inspired nanocrystalline HA/HRN coating. (A) The schematic illustration of coating nano HA/HRN on titanium, (B) the nanostructured HA/HRN coating mimics the natural bone matrix which consists in part of triple helices of collagen assembled with nanocystalline HA, (C) SEM images of biomimetic HA with 0.I mg/ml HRN$\mathrm{KI}$ coating on a porous carbon TEM grid (prepared by reacting $\mathrm{CaCl}_{2}$ with $\mathrm{Na}_{2} \mathrm{HPO}_{4}$ for 2 minutes on a TEM grid covered by $\mathrm{HRN}-\mathrm{KI}$ ), and (D) only $\mathrm{HA}$ coating on TEM grid (control, 2 minute reaction). 
bone tissue formation possibly contributing to lower implant failure rates.

Importantly, nano HA/HRNs were coated on titanium by adsorption, which was adopted as a model coating method in this study. This coating method could be improved by using commercially available coating techniques (such as the widely used plasma-spray process, sol-gel processing, spin coating, electrospinning, newly developed IonTite ${ }^{\mathrm{TM}}$ methods [Sato et al 2006], etc), which may contribute to more surface coverage and coating strength for orthopedic applications.

Lastly, previous studies have demonstrated that HRN-K1 have the potential to increase new bone growth when coated on titanium or hydrogels because of its nanoscale biologically-inspired features and rich lysine moieties (Chun et al 2004; Zhang et al 2008b). In the current study, the concentration of HRNs that osteoblasts interacted with was below $0.001 \mathrm{mg} / \mathrm{ml}$ due to dilution effects of co-coating HRNs and HA (eg, some HRNs may be underneath the HA and not exposed on the surface). Since it has been demonstrated that higher concentrations of HRNs on hydrogels (such as $0.01 \mathrm{mg} / \mathrm{ml}$ ) can enhance osteoblast adhesion compared with low HRN concentration coatings (Zhang et al 2008b), it anticipated that increasing HRN concentration on the HA/HRN coating can further augment osteoblast adhesion. Clearly, this should be the focus of further studies.

\section{Conclusions}

In summary, different grain sizes of nanocrystalline HA were synthesized in this study and co-coated with a low concentration (specifically, $0.001 \mathrm{mg} / \mathrm{ml}$ ) of HRN-K1 on titanium. The present study demonstrated that HRNs had a high affinity with nanocrystalline HA. Furthermore, biomimetic nano HA/ HRN coatings offer advantages over traditional orthopedic implant materials (such as uncoated titanium) by enhancing osteoblast adhesion and, thus, deserve further investigation for improving orthopedic applications.

\section{Acknowledgments}

This research was supported by NIH Grant \# 1R21AG027521. We would like to thank Ms. Oluwaseun Adegbesan and the Brown University Research Experiences for Teachers Program for research assistance. The authors report no conflicts of interest.

\section{References}

[AAOS] American Academy of Orthopedic Surgeons. 2003. Research and scientific affairs - AAOS [online]. Accessed on April 8, 2008. URL: http://www.aaos.org/research/research.asp.
Balasundaram G, Sato M, Webster TJ. 2006. Using hydroxyapatite nanoparticles and decreased crystallinity to promote osteoblast adhesion similar to functionalizing with RGD. Biomaterials, 27:2798-805.

Bigi A, Bracci B, Cuisinier F, et al. 2005. Human osteoblast response to pulsed laser deposited calcium phosphate coatings. Biomaterials, 26:2381-9.

Chang C, Wu J, Mao D, et al. 2006. Mechanical and histological evaluations of hydroxyapatite-coated and noncoated Ti6A14V implants in tibia bone. J Biomed Mater Res, 56:17-23.

Choi JW, Cho HM, Kwak EK, et al. 2004. Effect of Ag-doped hydroxyapatite as a bone filler for inflamed bone defects. Key Eng Mater, 254-256:47-50.

Chun AL, Moralez JG, Fenniri H, et al. 2004. Helical rosette nanotubes: a more effective orthopaedic implant material. Nanotechnology, 15: S234-9.

Chun AL, Moralez JG, Webster TJ, et al. 2005. Helical rosette nanotubes: A biomimetic coating for orthopedics? Biomaterials, 26:7304-9.

Ciobanu G, Carja G, Ciobanu O, et al. 2007. SEM and EDX studies of bioactive hydroxyapatite coatings on titanium implants. Micron, Dec 5 , Epub ahead of print.

Duan K, Wang R. 2006. Surface modifications of bone implants through wet chemistry. J Mater Chem, 16:2309-21.

Evis Z, Sato M, Webster TJ. 2006. Increased osteoblast adhesion on nanograined hydroxyapatite and partially stabilized zirconia composites. J Biomed Mater Res, 78A:500-7.

Fenniri H, Mathivanan P, Vidale KL, et al. 2001. Helical rosette nanotubes: design, self-assembly and characterization. J Am Chem Soc, 123: 3854-5.

Hoexter DL. 2002. Bone regeneration graft materials. J Oral Implantol, 28:290-4.

Ioku K, Yoshimura M. 1991. Stoichiometric apatite fine single crystals by hydrothermal synthesis. Phosphorus Res Bull, 1:15-20.

Jayaraman M, Meyer U, Buhner M, et al. 2004. Influence of titanium surfaces on attachment of osteoblast-like cells in vitro. Biomaterials, 25:625-31.

Kaplan FS, Hayes WC, Keaveny TM, et al. 1994. Form and function of bone. In: Buckwalter JA, Einhorn TA, Sinmon SP (eds). Orthopedic Basic Science. Rosemont, IL: American Academy of Orthopaedic Surgeons. pp 127-85.

Lopez-Macipe A, Rodriguez-Clemente R, Hidalgo-Lopez A, et al. 1998. Wet chemical synthesis of hydroxyapatite particles from nonstoichiometric solutions. J Mater Synth Process, 6:21-6.

Narayanan R, Kim S, Kwon T, et al. 2008. Nanocrystalline hydroxyapatite coatings from ultrasonated electrolyte: Preparation, characterization, and osteoblast responses. J Biomed Mater Res, Feb 6. Epub ahead of print.

Sammarco VJ, Chang L. 2002. Modern issues in bone graft substitutes and advances in bone tissue technology. Foot Ankle Clin, 7:19-41.

Sato M, Slamovich EB, Webster TJ. 2005. Enhanced osteoblast adhesion on hydrothermally treated hydroxyapatite/titania/poly(lactide-coglycolide) sol - gel titanium coatings. Biomaterials, 26:1349-57.

Sato M. 2006. Nanophase hydroxyapatite coatings for dental and orthopedic applications [Ph.D. thesis]. School of Materials Engineering, Purdue University, West Lafayette, IN.

Sato M, Sambito MA, Aslani A, et al. 2006. Increased osteoblast functions on undoped and yttrium-doped nanocrystalline hydroxyapatite coatings on titanium. Biomaterials, 27:2358-69.

Sato M, Aslani A, Sambito MA. et al. 2007. Nanocrystalline hydroxyapatite/titania coatings on titanium improves osteoblast adhesion. J Biomed Mater Res Part A, 84A:265-72.

Shibli SMA, Mathai S. 2008. The role of calcium gluconate in electrochemical activation of titanium for biomimetic coating of calcium phosphate. $J$ Biomed Mater Res, Feb 6, Epub ahead of print.

Siegel RW, Fougere GE. 1995. Mechanical properties of nanophase metals. Nanostruct Mater, 6:205-16.

Teng S, Lee E, Park C, et al. 2008. Bioactive nanocomposite coatings of collagen/hydroxyapatite on titanium substrates. J Mater Sci Mater Med, 19(6):2453-61. 
Wang M. 2004. Bioactive materials and processing. In: Shi D (ed). Biomaterials and Tissue Engineering. Berlin, Heidelberg: Springer. pp 1-82.

Webster TJ, Siegel RW, Bizios R. 2000. Specific proteins mediate osteoblast adhesion on nanophase ceramics, J Biomed Mater Res, 51:475-83.

Webster TJ. 2001. Nanophase ceramics: the future orthopedic and dental implant material. In: Ying JY (ed). Nanostructured Materials (Advances in Chemical Engineering). San Diego, CA: Academic Press. pp 125-66.

Webster TJ, Ergun C, Doremus RH, et al. 2002. Hydroxylapatite with substituted magnesium, zinc, cadmium, and yttrium. II. Mechanisms of osteoblast adhesion. J Biomed Mater Res, 59:312-17.
Zhang LJ, Sirivisoot S, Balasundaram G, et al. 2008a. Nanomaterials for improved orthopedic and bone tissue engineering applications. In: Basu B, Katti DS, Kumar A (eds). Advanced Biomaterials: Fundamentals, processing and applications. Hoboken, NJ: John Wiley and Sons Inc., in press.

Zhang LJ, Ramsaywack S, Fenniri H, et al. 2008b. Enhanced osteoblast adhesion on self-assembled nanostructured hydrogel scaffolds. Tissue engineering, in press. 
